PONTIFÍCIA UNIVERSIDADE CATÓLICA DO RIO DE JANEIRO

\title{
Pesquisa de Satisfação dos Clientes do Restaurante Hollandaise
}

\author{
Gustavo Miraldes Bulus \\ Trabalho de Conclusão de Curso
}

CENTRO de CIÊNCIAS SOCIAIS - CCS

DePARTAMENTO de AdMINISTRAÇÃo

Graduação em Administração de Empresas

Orientadora: Marina Frid 


\section{Agradecimentos}

Gostaria primeiramente de agradecer a DEUS que me ajudou nos momentos mais difíceis da minha vida, momentos que somente eu e meus familiares sabem o que eu passei. Meu pai, Abdo, e minha mãe, Marta, merecem todos os agradecimentos do mundo por terem me apoiado durante toda a trajetória acadêmica e profissional. Meu irmão, Daniel, e minha irmã, Fernanda, foram com os meus pais pessoas fundamentais para a formação do meu caráter, pelo apoio a minha formação acadêmica e pelo suporte na vida pessoal e profissional. Com isso, sem dúvidas, gostaria de dizer que a família é o bem mais precioso que temos. Não podia deixar de citar meu tio, Aloisio, que durante a minha trajetória acadêmica, pessoal e profissional sempre buscou me ajudar da melhor forma possível. Gostaria de agradecer especialmente a toda a equipe do restaurante Hollandaise.

Gostaria de agradecer aos meus amigos Gabriel Ribeiro, Raphael Ribeiro, Matheus Valentim, Luciano Pereira, Bernardo Guerra, Antonio D'Elia e Marcelo Papa e Rodolfo Protector por estarem caminhando comigo e me ajudarem durante essa longa jornada que chamamos de "vida" ou até mesmo de "aprendizado". Agradeço a minha academia Gracie Barra e ao meu professor Jefferson Moura que me deram bastante disciplina para seguir a minha vida.

Obrigado a minha orientadora Marina Frid por todo o suporte dado com simpatia, boa vontade e atenção durante a orientação da Monografia.

Dedico essa monografia ao meu grande amigo, Guilherme Pimentel, que aos 17 anos nos deixou devido a um câncer e foi morar junto com o papai do céu. Que Deus esteja cuidando de você e te iluminando todos os dias.

“...Não deixe que ninguém tire sua esperança..." - Papa Francisco 


\section{Resumo}

A presente monografia tem como escopo analisar a qualidade do serviço prestado no restaurante Hollandaise, localizado na Barra da Tijuca, na cidade do Rio de Janeiro. Para avaliar o grau de satisfação dos clientes em relação ao referido estabelecimento, foi realizada uma pesquisa através de um questionário apresentado aos frequentadores ao final de suas refeições. $O$ restaurante tem uma média de publico mensal de 5.000 consumidores e nessa pesquisa foram colhidas 251 respostas. Com base nas respostas coletadas, o pesquisador fez uma análise dos dados através da ferramenta de pesquisa SURVIO. Com base nos resultados, podemos classificar que o restaurante Hollandaise tem um elevado grau de satisfação dos seus consumidores.

Palavras-chave. Qualidade, Serviços, Restaurante, Hollandaise, Cliente, Satisfação do Cliente.

\section{Abstract}

This monograph is scoped to analyze the quality of service in Hollandaise restaurant, located in Barra da Tijuca, in the city of Rio de Janeiro, to assess the degree of customer satisfaction in relation to such business, a survey was conducted through a questionnaire presented to customers at the end of meals. The restaurant has an average monthly of 5,000 consumers and this survey were collected 251 responses. Based on the collected answers, the researcher made an analysis of the data by SURVIO search tool. Based on the results, we can classify the restaurant Hollandaise has a high degree of satisfaction of its consumers.

Key-words. Quality, Services, Restaurant, Hollandaise, Customer, Customer Satisfaction. 


\section{Sumário}

1 O tema e o problema de estudo 1

1.1. Introdução ao tema e ao problema do estudo 1

1.2. Objetivo, delimitação e foco do estudo 3

1.3. Justificativa e relevância do estudo 4

2 Revisão de literatura 8

2.1. Atendimento 8

2.2. Qualidade em Serviços 10

2.3 Marketing de Serviços 11

2.4 Satisfação dos clientes 12

$\begin{array}{ll}2.5 \text { Marketing de Relacionamento } & 15\end{array}$

3. Metodos e procedimentos de coleta e de análise de dados do estudo 17

3.1 Fontes de informação selecionadas para coleta de dados no estudo 19

$\begin{array}{ll}3.2 & \text { Limitações do Estudo } \\ & 19\end{array}$

4 Apresentação e análise dos resultados 20

5 Conclusões e recomendações para novos estudos 26

6 Referências Bibliográficas $\quad 28$ 


\section{Lista de figuras}

Figura 1 : Pesquisa de Satisfação do Hollandaise - Frente ............................ 18

Figura 2 : Pesquisa de satisfação Hollandaise - Verso .................................. 18

\section{Lista de tabelas}

Tabela 1: Gênero dos consumidores..................................................... 20

Tabela 2: Idade dos consumidores....................................................... 21

Tabela 3: Grau de satisfação da Comida .................................................... 21

Tabela 4: Grau de satisfação da Bebida......................................................... 22

Tabela 5: Grau de satisfação do Atendimento ................................................ 23

Tabela 6: Grau de satisfação do Ambiente.................................................. 23

Tabela 7: Grau de satisfação do Custo-benefício ............................................ 24 


\section{0 tema e o problema de estudo}

Neste capítulo será feita uma introdução ao tema e ao problema do estudo, de forma a contextualizar o leitor em relação ao trabalho realizado. Para tanto, será apresentado o problema e explicado por que ele é importante.

Na seção seguinte serão estabelecidos os objetivos intermediários, como forma de delimitar o trabalho. Explicados os objetivos da pesquisa e a importância do tema, será feita uma explicação da relevância deste tema para o contexto e qual a contribuição espera-se prover à comunidade a partir deste estudo.

\subsection{Introdução ao tema e ao problema do estudo}

O presente estudo pretende analisar a qualidade do serviço prestado no restaurante Hollandaise, que fica localizado na praia da Barra da Tijuca, na cidade do Rio de Janeiro, através da avaliação do grau de satisfação do cliente final com relação ao serviço ali oferecido. Os resultados da investigação podem possibilitar a identificação de eventuais ações a serem tomadas para melhorar cada vez mais o serviço fornecido pelo estabelecimento. Primeiramente, é importante mencionar que o restaurante desempenha atividades no ramo de alimentação há mais de 4 anos, tendo sido inaugurado no dia 10 de agosto de 2010. O nome do restaurante surgiu através do Molho "Hollandaise" que é uma emulsão de gema de ovo e manteiga, geralmente temperada com suco de limão, sal e um pouco de pimenta branca ou pimenta caiena. O sabor é rico e amanteigado, porém não tão forte a ponto de se sobrepor ao sabor dos outros ingredientes dos pratos. O molho "Hollandaise" é um dos cinco principais molhos no repertório da alta gastronomia francesa. Reza a lenda que o molho surgiu em um jantar servido no encontro dos reis da França e Holanda. Os proprietários do restaurante optaram por esse nome devido a sua associação com a alta culinária e os mesmos queriam passar a impressão de uma gastronomia de qualidade aos seus clientes. O restaurante trata-se de um mix de bistrô e brasserie, que foi criado com o intuito de ser um restaurante charmoso com um clima descontraído 
que, ao mesmo tempo, oferece pratos sofisticados e bebidas diferenciadas, com um preço acessível ao cliente. Assim sendo, o local atrai tanto aqueles que pretendem tomar uma cerveja e comer alguns aperitivos, quanto aqueles que pretendem fazer uma refeição completa e sofisticada, acompanhando um bom vinho, tudo isso com um preço acessível, considerando o serviço fornecido.

O restaurante Hollandaise é considerado como um restaurante de culinária internacional, que comporta 180 lugares, possui uma ampla varanda e um lounge super aconchegante. $O$ ticket médio do restaurante, que consiste no valor das vendas dividido pelo número de clientes atendidos durante determinado período, gira em torno de $R \$ 120,00$ por pessoa. $O$ estabelecimento atende uma média de 5.000 consumidores por mês. Recentemente o restaurante Hollandaise recebeu o Certificado de Excelência no site "TripAdvisor". O site funciona em 45 países de todo o mundo e recebe cerca de 340 milhões de visitantes mensais e mais de 225 milhões de avaliações e opiniões sobre mais de 4,9 milhões de hotéis, restaurantes, bares, lanchonetes e atrações turísticas. O "TripAdvisor" também possui o "TripAdvisor for Business", um setor que se dedica a oferecer à indústria turística o acesso aos milhões de visitantes mensais do "TripAdvisor". O certificado de excelência é recebido quando diversos visitantes do site classificam como excelente a sua opinião em relação ao local visitado. Hoje o restaurante ocupa a $371^{\circ}$ posição de $9.070^{\circ}$ no Ranking de Restaurantes do "TripAdvisor" no Rio de Janeiro

- Como é comentado pelos proprietários de restaurante da Barra da Tijuca, a escolha do nome, a exata localização, o público-alvo de um restaurante, tem grande influência nos rumos que aquele estabelecimento irá tomar: seja em termos de faturamento, horário de funcionamento ou até mesmo os tipos de comida e bebida que irá oferecer aos clientes. E todos esses fatores podem contribuir para o insucesso de um novo estabelecimento. Segundo Luiz Guimarães, proprietário da "Le Depanneur" e da "Deli Golden Green", atrair os clientes e torna-los fiéis ao estabelecimento pode ser uma das tarefas mais difíceis neste mercado tão incerto e instável, sendo certo que, para atingir tal objetivo, o serviço final (do garçom) é fundamental. Assim sendo, torna-se imprescindível a busca constante pela melhoria na qualidade dos serviços prestados, além de um planejamento impecável e um amplo conhecimento no setor. Desta forma, a análise da qualidade dos serviços prestados pelo restaurante Hollandaise será feita por meio de uma pesquisa quantitativa com os clientes, realizada no período de 1 (um) mês no restaurante Hollandaise, que 
permitirá a identificação dos pontos fortes e fracos do serviço prestado no referido estabelecimento, do ponto de vista do consumidor.

A pesquisa acima mencionada analisará criteriosamente os seguintes pontos: (i) atendimento, (ii) bebidas; (iii) comida ; (iv) ambiente; (v) relação custobenefício, com o intuito de identificar claramente quais são os pontos fortes e os pontos fracos dos serviços ali prestados e em qual momento eles ocorrem (se são um erro de processo ou de atendimento), permitindo que sejam indicadas propostas eficazes para a melhoria daquele estabelecimento como um todo.

Por fim, cumpre observar que os sócios do restaurante Hollandaise concordaram em fazer a pesquisa objeto deste estudo, uma vez que eles desejam aprimorar cada vez mais os serviços oferecidos pelo restaurante e compreendem que, para tanto, é necessário identificar o grau de satisfação dos clientes e identificar possíveis problemas para que eles possam buscar soluções.

Neste contexto, a presente monografia estudará os principais aspectos dos pontos acima mencionados, com o intuito de identificar, analisar e avaliar o grau de satisfação dos clientes do restaurante Hollandaise, permitindo, portanto, que sejam indicadas propostas eficazes para a melhoria daquele estabelecimento como um todo.

\subsection{0bjetivo, delimitação e foco do estudo}

Como mencionado acima, o objetivo final deste trabalho é avaliar a qualidade do serviço prestado pelo restaurante Hollandaise a partir do ponto de vista do consumidor. Para tanto será avaliado o grau de satisfação dos clientes do restaurante Hollandaise, com a finalidade de identificar, analisar e avaliar a qualidade dos serviços oferecidos pelo restaurante, por meio de uma pesquisa quantitativa junto aos consumidores presentes no local.

O resultado deste trabalho, caso seja utilizado como feedback para os empresários e consumidores, poderá ser importante para a revisão e o aumento da efetividade de suas estratégias e opções de consumo no mercado gastronômico. O estudo será feito no restaurante Hollandaise, localizado na Barra da Tijuca, Estado do Rio de Janeiro, mediante a elaboração de uma pesquisa quantitativa. A partir de tal análise, será possível propor determinadas ações capazes de gerar uma melhoria significante nos serviços oferecidos pelo restaurante Hollandaise. Como forma de alcançar o objetivo final, deverão ser alcançados, primeiramente, quatro objetivos intermediários: 
(i) Entrevistas com proprietários/gerentes de restaurante da Região da Barra da Tijuca

(ii) Montar um questionário para coletar opiniões dos consumidores

(iii) Medir o grau de satisfação de cada item do questionário

(iv) Análise dos dados da pesquisa

\subsection{Justificativa e relevância do estudo}

O presente estudo visa identificar o grau de satisfação dos clientes do restaurante Hollandaise, mediante a realização de uma pesquisa quantitativa na qual é apresentado um questionário ao consumidor ao final de seu atendimento no restaurante, que pretende verificar a percepção dos consumidores sobre a qualidade dos serviços prestados e que será fundamental para a melhoria nos serviços oferecidos pelo restaurante Hollandaise.

O Setor de Bares e Restaurantes é extremamente importante para a economia brasileira, por isso podemos considerar a relevância desse trabalho. Os bares e restaurantes movimentam cerca de $2,4 \%$ do Produto Interno Brasileiro (PIB) e o setor emprega cerca de 6 milhões de brasileiros, cerca de $8 \%$ dos empregos diretos segundo dados do Governo Brasileiro. Segundo dados da ABIA (Associação Brasileira das Industrias de Alimentação) o faturamento desse setor cresce de ano em ano, em 2007 os bares e restaurantes brasileiros faturaram $R \$ 50,8$ bilhões, número que chegou a $R \$ 84$ bilhões em 2011. Em 2013 o setor faturou cerca de $R \$ 116,5$ bilhões, um incremento de $R \$ 16$ bilhões em relação a 2012. O crescimento do setor fica em torno de $10 \%$ ao ano. A informação impressiona quando no ano de 1995 o gasto com o orçamento alimentício feito para de casa era de 19\%, em 2013 atingiu 32,9\% e em 2014 gasto com o orçamento alimentício feito fora de casa ficou em torno de $38 \%$, segundo pesquisa realizada pelo Instituto Federal de Brasília. A média de gasto por refeição no Brasil era de $R \$ 14,39$ (Classe $A$ : $R \$ 20,02$; $B$ : $R \$ 15,08$; e $C: R \$$ $11,47)$ por pessoa. Em geral, nota-se que o consumidor está mais disposto a gastar seu dinheiro durante as horas de lazer e o jantar. $60 \%$ das refeições são feitas no próprio local, $30 \%$ prefere levar para casa, 3\% compra pelo drive thru e $7 \%$ solicita o serviço de entrega em sua residência, segundo o Instituto Federal de Brasília. 
O setor de restaurantes vem se expandindo na região da Barra da Tijuca, onde, a partir de 2010, diversos restaurantes se instalaram para atender à crescente demanda da região, tais como, "Pobre Juan", "L'Entrecote", "Hollandaise", "Gero", "Duo", "Naga", dentre outros. A realização da Copa do Mundo no Brasil, em 2014, estimulou investimentos nas cidades, particularmente em hotéis, estabelecimentos e toda rede que supre o food service, que deixaram um legado para um setor que ainda tem muito potencial, inclusive no Rio de Janeiro que sediou diversos jogos da competição e a final da Copa do Mundo. Mas o cenário é ainda mais animador, visto que o Rio de Janeiro irá sediar as Olimpíadas de Verão em 2016. A cidade espera receber um grande número de estrangeiros, turistas, imprensa, equipes esportivas estão sendo feitos diversos investimentos na região do Rio de Janeiro, com certeza as Olimpíadas de Verão irão impactar diretamente na economia da cidade, principalmente, no setor de bares e restaurantes. Segundo Rodolfo Protector, sócio-gerente do restaurante Hollandaise, o restaurante faturou cerca de 35\% a mais na Copa do Mundo de 2014 do que nos 3 meses anteriores ao evento.

Mas não devemos achar que o setor de Bares e Restaurantes é um "mar de rosas" no Rio de Janeiro. Como comentam alguns comerciantes que a instabilidade dos restaurantes é muito grande. Segundo Jose Luís Guimarães, proprietário do restaurante/lanchonete "Golden Sucos" (a mais de 10 anos no mercado) existem épocas de baixa temporada e alta temporada. Jose afirma que as condições climáticas impactam muito no negócio, quando está muito quente ou muito frio o movimento tende a cair. O mais impressionante é que Jose afirmou que existem dias que a Golden Sucos fatura cerca de $250 \%$ a mais do que no mesmo dia de uma semana anterior. Segundo o empresário o movimento é imprevisível. Quando falamos em estatística os números não animam, por isso que os prestadores de serviços devem ficar cada vez mais atentos ao grau de satisfação de seus clientes. De acordo com a Associação Brasileira de Bares e Restaurantes (Abrasel), em pesquisa realizada em 2014 cerca de 35\% dos novos empreendimentos fecham antes do primeiro ano, quase $50 \%$ não se mantêm por dois anos e apenas 3 entre 100 restaurantes sobrevivem aos primeiros dez anos de funcionamento.

Segundo CODEÇO, os restaurantes cariocas estão passando por uma fase de crise, no ano de 2010 a 2013 a inflação estava em 25\% enquanto os alimentos e bebidas subiram cerca de 40\%. A preocupação fica ainda maior quando falamos sobre os preços dos alugueis e impostos que juntos consomem cerca de $22 \%$ do orçamento dos restaurantes. A solução encontrada pelos 
restaurantes diante da crise foi diminuir a sua margem de lucratividade, 0 restaurateur Antonio Perico, filho do fundador do Antiquarius relembra o tempo que a margem de lucro liquido era de $40 \%$ no final do mês e hoje o valor não ultrapassa de 12\% (Autor: Fabio Codeço Ano: 2014). O resultado é que manter uma empresa do setor lucrativa exige competência, boa gestão, muito trabalho e um cliente extremamente satisfeito.

Segundo o SindRio (Sindicatos de Hotéis, Bares e Restaurantes) no ano de 2012 havia cerca de 15 mil estabelecimentos, no município do Rio de Janeiro e cerca de 120 mil empregos diretos gerados por alimentação e hospedagem. Desta forma, fica claro que a quantidade de empregos gerada anualmente no ramo de restaurantes, bem como o recorrente fechamento de portas de diversos estabelecimentos, demonstra não só a relevância da pesquisa ora desenvolvida, como também a evolução da preocupação dos empreendedores com a satisfação constante de seus clientes. Diante disso, tal estudo se mostra extremamente relevante para os empreendedores do ramo de restaurantes (ou aqueles que pretendem entrar no referido ramo), na medida em que identifica pontos a serem observados por todos os estabelecimentos a fim de agradar seus clientes, uma vez que a pesquisa leva em consideração o ponto de vista do consumidor, permitindo, assim, entender quais são os pontos considerados mais relevantes pelos consumidores ao chegarem em um restaurante e quais praticas são determinantes para fazer com que eles retornem ao local. Além disso, todos aqueles que trabalham neste ramo também podem se beneficiar com o presente estudo, podendo aprender a melhorar sua atuação com base nos pontos ora indicados nesta pesquisa, propor melhorias em seus ambientes de trabalho e buscar sempre corrigir erros que afetam os padrões de qualidade, e, consequentemente, se desenvolver cada vez mais em sua carreira profissional.

Não obstante, a relevância deste estudo também se estende aos consumidores que passam a ter uma visão positiva do estabelecimento, uma vez que tal local demonstra extrema preocupação com a satisfação de seus clientes, sendo este o principal foco do atendimento. Assim sendo, o padrão dos serviços nos restaurantes estarão sempre buscando uma melhoria a fim de atingir a plena satisfação do público. Por fim, destaca-se, ainda, a relevância acadêmica do presente estudo que servirá como base para novas pesquisas acadêmicas no que diz respeito aos problemas de atendimento de uma forma geral, e, especificamente no ramo de restaurantes. Pelo exposto, o estudo aqui desenvolvido pode se tornar uma ferramenta importante para guiar novos estabelecimentos que fecham suas portas por motivos relacionados ao serviço 
fornecido, uma vez que permitirá uma melhora significativa na conquista dos clientes. Assim sendo, a geração de empregos neste ramo poderá continuar com a curva de crescimento cada vez maior. 


\section{Revisão de literatura}

Neste capítulo serão apresentados e discutidos aspectos conceituais e estudos relacionados ao tema, que servirão de base para a análise a ser realizada.

Antes de esclarecer a metodologia e os resultados da pesquisa, é importante que alguns conceitos sejam elucidados uma vez que eles serão utilizados ao longo deste trabalho.

\subsection{Atendimento}

É exercício de satisfazer as necessidades, anseios, e desejos do cliente. ZENONE (2003 p.16) explica que os clientes estão cada vez mais exigentes e, como consequência, as empresas enfrentam mais dificuldades para desenvolver seus negócios, tendo que reestruturar sua maneira de atuar no mercado. Segundo LARENTIS (2009), não é novidade nos dias atuais, a importância dada ao consumidor e aos clientes, as empresas estão buscando diversas formas de oferecer o que os consumidores e torna-los leais a elas.

MARICATO (2001) defende que o mau atendimento é uma das principais causas do não regresso de um cliente ao restaurante. Segundo o autor, pesquisas indicam que $70 \%$ dos clientes são perdidos em função da má qualidade dos serviços, embora apenas $4 \%$ destes clientes reclamam.

Pode-se citar exemplos de mau atendimento em restaurantes quando o garçom está mal humorado e não atende as expectativas do cliente, quando a comida chega fora do padrão para o consumidor, quando o ambiente não está higiênico e até mesmo quando existe demora na recepção ou no recebimento da conta. Assim sendo, quanto mais refinado for o conceito e o tipo de público do estabelecimento, mais impecável deve estar o atendimento. Para tanto, é interessante ter em mãos um check-list dos principais itens que possam gerar qualquer interferência no atendimento final do cliente. Inicialmente, é importante ficar claro que o atendimento vai muito além de apenas servir o prato ao cliente, trata-se de tentar antecipar qualquer solicitação que possa vir a ser feita, ainda que não seja do produto principal do estabelecimento. É interessante ter em 
mãos, por exemplo, contatos de táxi, endereço de motéis, isqueiro, remédios para dor de cabeça, dentre outros, para que seu cliente saia dali com a melhor impressão possível. Pensar fora da caixa faz com que o cliente fique extremamente satisfeito e impressionado com o tratamento que lhe foi dispendido. Muitos estabelecimentos contam com a figura do dono do local para garantir ao cliente um sentimento de confiança, status e familiaridade, especialmente em bistrôs. Nesses casos, é interessante que o cliente seja cumprimentado e recebido pelo dono em sua chegada.

Segundo Rodolfo Protector, gerente do restaurante Hollandaise, existem alguns pontos para saber lidar com qualquer adversidade que porventura possam surgir, tais como:

(i) Eventuais reclamações sobre o pedido formulado - nestes casos, o garçom deve tratar o cliente com a maior cortesia possível, lembrando que o cliente sempre tem razão. É interessante que o gerente seja chamado para que o cliente se sinta mais confiante e importante;

(ii) Higiene do local- É redundante afirmar que a higiene de qualquer estabelecimento deste setor deve ser impecável, e os equipamentos, utensílios, cardápios, guardanapos, preparados antes do início de cada expediente. Qualquer questionamento neste sentido deve ser imediatamente dirigido à gerência para que sejam tomadas todas as providências necessárias;

(iii) Ausência de funcionários chave que normalmente garantem a excelência no atendimento - Aqui o estabelecimento pode criar mecanismos que evitem tais ausências em caso de fatores externos, como, por exemplo, disponibilizar transporte para tais funcionários em caso de transito em dias de chuva forte e/ou greves e manifestações.

(iv) Organização da fila de espera - Muitas vezes, ocorrem questionamentos envolvendo a fila de espera. Assim sendo, a ordem de chegada deve ser respeitada sempre que possível e nos casos em que isso não acontece devem ser repassados aos clientes os motivos que levaram a esse "distúrbio", de preferência, pelo gerente responsável ou até pelo dono para que o cliente sinta que seu "distúrbio" não passou desapercebido.

(v) Temperatura das bebidas servidas à mesa - no que diz respeito às bebidas é importante observar as características envolvidas com o preparo e armazenagem de cada tipo. O chope, por exemplo, deve ser servido em uma temperatura entre 3 e 4 graus no verão e 5 e 6 graus no inverno, um colarinho de pelo menos 2 dedos e não pode ter mais de 10 dias de fabricação. $O$ vinho 
não pode ser armazenado em locais expostos ao sol, e as garrafas não devem ser deixadas em pé.

Com relação aos garçons, conclui-se que o comportamento e o treinamento das equipes devem variar de acordo com o estabelecimento em que trabalham, devendo os donos estarem sempre procurando melhorar o atendimento e fiscalizando constantemente a interação entre funcionários e os clientes para que não haja um afastamento em decorrência deste fator. Cada cliente tem sua peculiaridade que deve ser respeitada, de forma a agradar a todos.

\subsection{Qualidade em Serviços}

O conceito de qualidade nos serviços é abordado por diferentes autores. Para CAMPOS (1992, p.2), "um produto ou serviço de qualidade é aquele que atende perfeitamente, de forma confiável, de forma acessível, de forma segura e no tempo certo às necessidades do cliente". A qualidade em serviços consiste em uma avaliação ao longo prazo do serviço final, diferente da satisfação do cliente que é uma medida de curto prazo. Os conceitos de satisfação e qualidade em serviços de certa forma estão entrelaçados mas a relação entre eles não é evidente. Segundo HOFFMAN (2013) a diferenciação na qualidade dos serviços oferecidos podem levar a ganhos na participação de mercado e isso pode gerar a grande diferença entre o fracasso e o sucesso financeiro.

Desta forma, percebe-se que a qualidade é um conceito subjetivo, "Se um cliente julga ter recebido um serviço cuja qualidade supera às suas expectativas, ele considera ter recebido uma prestação de qualidade superior e se sente inclinado a utilizá-lo novamente, ou recorrer a empresa que o prestou." (KOTLER e ARMSTRONG, 2003, p. 415).

JURAN (1992), por sua vez, define qualidade em serviços da mesma forma que sua definição genérica de "adequação ao uso" como sendo a capacidade de um serviço de satisfazer as necessidades de um cliente no momento em que tal serviço é prestado. Diante de tais definições, verifica-se que a qualidade possui dois componentes, sendo eles: (i) o serviço propriamente dito e (ii) a forma como ele é percebido pelo consumidor. Aqui ocorre uma comparação constante entre a qualidade que é esperada pelo consumidor e a qualidade que de fato é oferecida pelo prestador de serviços. Dentro dessa percepção, diversos fatores estão envolvidos, como, por exemplo, grau de 
cortesia, interesse, atenção dedicada ao cliente. Dessa forma, é importante que as empresas tentem agradar o cliente tanto de maneiras técnicas (no serviço que vai ser prestado) como também com ações simpáticas, de forma a complementar a execução do serviço e agradar o cliente.

\subsection{Marketing de Serviços}

Os serviços se tornaram parte importante da economia global nas últimas décadas, uma vez que representam parcela significativa do produto interno bruto de vários países, principalmente dos países industrializados. O Marketing de serviços, por sua vez, é um campo recente que surgiu atrelado à necessidade de identificação da demanda do consumidor final, de forma a melhor atendê-lo. Segundo COBRA (1986, p.3): "O marketing de serviços é um campo de investigação recente e ainda em fase de estruturação". Os serviços de Marketing podem ser entendido como todos os fatores que auxiliam a empresa a atender a demanda do mercado para os seus produtos, por meio da elaboração de pesquisas de mercado. KOTLER (1998, p.412), conceitua serviço da seguinte forma: "Serviço é qualquer ato ou desempenho que uma parte possa oferecer a outra e que seja essencialmente intangível e não resulte na propriedade de nada”. Já LOVELOCK (2001) define serviços como um ato ou desempenho oferecido por uma parte ou outra.

De acordo com KOTLER (1998, p.414), os serviços possuem quatro características: Intangibilidade, Inseparabilidade, Variabilidade e Perecibilidade. Em linhas gerais, as definições que propõe para cada um desses conceitos são apresentadas a seguir:

Intangibilidade: Segundo o autor, a intangibilidade do serviço resulta de não poder ser visto, provado, sentido, ouvido ou cheirado, antes de ser comprado. Assim sendo, os consumidores buscam analisar os sinais de qualidade daquele serviço antes de optarem por sua escolha (tais como: localização, o ambiente, os funcionários, atendimento, equipamentos, preço, dentre outros). Para KOTLER (1998, p.414): "A tarefa do fornecedor é administrar a evidência, tangilizar o intangível".

Inseparabilidade: A inseparabilidade está associada ao fato de que a produção de um serviço não pode ser separada de seu consumo pelo cliente, uma vez que geralmente os serviços são produzidos e consumidos simultaneamente. Desta 
forma, tanto o fornecedor quanto o consumidor afetam diretamente o resultado do serviço.

Variabilidade: os serviços possuem uma variabilidade ampla uma vez que dependem de quem os executa, de quem os recebe e do lugar onde são prestados. Cientes de tal variabilidade, os compradores de serviços normalmente procurarão saber opiniões diversas antes de escolher o seu fornecedor.

Perecibilidade: KOTLER (1998, p.416) define: "Serviços não podem ser estocados". A perecibilidade acontece porque os serviços não podem ser armazenados para uso futuro, somente podendo ser utilizados em determinado período de tempo. Portanto, devem ser planejados de acordo com a demanda existente.

É importante notar que o consumidor seleciona seus fornecedores por meio da análise de critérios que julga imprescindíveis para a satisfação de seus interesses. Diante disso, as empresas fornecedoras de serviços devem se antecipar de forma a facilitar as atividades de compra. Segundo McKenna (1999) o serviço não é considerado um evento e sim um processo de criação de um ambiente de informação, garantia e conforto ao consumidor.

As empresas prestadoras de serviços precisam se dedicar no sentido de construir uma boa reputação por meio da prestação de um bom serviço, buscando sempre um alto controle de qualidade. Para tanto, elas podem investir em ações como treinamento constante de seu pessoal, padronização do processo de prestação de serviço, acompanhamento da satisfação do consumidor por meio de pesquisas constantes. Neste sentido, LOVELOCK (2001) enfatiza que os serviços oferecidos devem ultrapassar as expectativas dos clientes, de forma a resultar em uma percepção positiva. Na mesma linha, GIANESI e CORRÊA (1996) afirmam que todo e qualquer cliente tem uma expectativa inicial em relação ao serviço oferecido e geralmente faz uma comparação entre o serviço efetivamente prestado e sua expectativa. Isso explica o fato de que a preocupação do prestador de serviços com a qualidade do atendimento e satisfação do cliente se tornou fator de extrema importância.

\subsection{Satisfação dos clientes}

De uma forma geral, cada vez mais os prestadores de serviços tem percebido que perder um cliente pode custar caro, uma vez que significa muito 
mais do que perder aquela única venda, mas sim toda a cadeia de compras daquele cliente durante toda uma vida de consumo (KOTLER E ARMSTRONG, 2003) e mais, toda a divulgação que aquele cliente fará acerca daquele serviço. Tal fato faz com que a satisfação do cliente seja fator primordial na atividade do prestador do serviço.

De acordo com KOTLER (1998, p.53): "O conceito de satisfação é o sentimento de prazer ou de desapontamento resultante da comparação do desempenho esperado pelo produto ou resultado em relação às expectativas da pessoa." Assim sendo, torna-se de extrema importância a preocupação do fornecedor em atender e, se possível, superar as expectativas do cliente. Os consumidores fazem uma constante comparação com relação ao serviço efetivamente prestado e a expectativa que ela tinha com relação a ele, sendo assim, se o retorno oferecido for menor que o esperado, o cliente estará insatisfeito. Toda e qualquer experiência anterior é levada em consideração nessa comparação, não somente as suas mas também de seu círculo social. Aqui, pode-se notar que a satisfação do ciente está diretamente relacionada ao Marketing de relacionamento, por meio do qual a empresa prestadora de serviços trabalha constantemente na construção de um relacionamento duradouro com seu cliente, se preocupando sempre com a constante satisfação deste.

Por outro lado, NICKELS e WOOD(1999) alertam que inúmeras empresas buscando alcançar retorno imediato, acabam sendo pressionadas e focam em maximizar seus lucros a curto prazo, de forma a dar um retorno rápido aos investidores. Tal postura pode prejudicar as empresas no longo prazo, uma vez que, geralmente nessa situação, acabam por dar menos importância à satisfação dos clientes e, consequentemente, não conseguem torna-lo um cliente fiel, perdendo-o para a concorrência e afetando a saúde financeira da empresa. Para viabilizar a análise dos fatores aqui elencados é necessário medir a satisfação do cliente. A melhor alternativa é perguntar ao cliente e observar seu comportamento. Assim sendo, a melhor forma de avaliar o serviço que está sendo prestado é através da elaboração de um questionário de pesquisa. Tal questionário deve conter perguntas adequadas àquela empresa e a aplicação do questionário deve ser feita de forma periódica de modo a obter uma análise satisfatória. Durante a análise da satisfação do cliente, é necessário entender que cada consumidor possui uma expectativa diferente com relação àquele serviço. Com a utilização periódica de um questionário de satisfação dos clientes, o fornecedor pode avaliar constantemente os serviços que vem sendo 
prestados, entendendo as necessidades de seus clientes, o que the permite aperfeiçoar cada vez mais suas atividades e atraindo sempre novos clientes. $O$ retorno daquele cliente é sinônimo de credibilidade para o estabelecimento.

De acordo com LEVY e WEITZ (2000), um fator de extrema importância na satisfação dos clientes é a atitude dos funcionários daquele prestador de serviços. É importante que os funcionários acreditem na empresa e saibam que necessitam de um relacionamento positivo com o cliente, em qualquer situação. Desta forma, a seleção, o treinamento e a motivação agregam valor ao serviço, uma vez que tem relação direta com a satisfação do cliente final. Uma empresa que possui funcionários competentes, motivados, com uma boa capacidade de resposta e interesse em atender o cliente final, buscando sempre a solução de eventuais problemas, conquista o cliente e demonstra confiabilidade e credibilidade daquela prestadora de serviços. Tal postura faz com que o cliente se sinta importante e entenda que é o ponto focal daquela empresa, que está sempre em busca de melhor satisfazê-lo. Essa constante busca é um investimento estratégico e tem se tornado cada vez mais um diferencial para empresas que buscam ser lideres neste mercado. Pelo exposto, conclui-se que focar na satisfação do cliente final é um investimento para a empresa prestadora dos serviços e que essa deve ser sua preocupação principal se quiser ter sucesso em seu negócio. Corroborando tal afirmação, vale mencionar que KOTLER (2000), sustenta que conquistar clientes novos custa entre 5 a 7 vezes mais caro do que manter sua clientela. Clientes fiéis tendem a indicar eventuais problemas que venham a ter na prestação daquele serviço, enquanto clientes infiéis simplesmente vão embora e não voltam mais. E ainda, podem fazer uma propaganda negativa de seu negócio, principalmente para seu círculo social.

Segundo KOTLER (1998) empresas inteligentes investem em confiança e em relacionamentos "ganha-ganha" a longo prazo com todos os players, sejam eles consumidores, distribuidores, revendedores e/ou fornecedores. Assim sendo, tais empresas estão preocupadas em atualizar e aperfeiçoar constantemente suas estratégias de fidelização dos clientes.

As novas tendências mundiais, principalmente no setor de comunicações, faz com que o cliente cada vez mais seja o ponto central quando se fala em prestação de serviços. Não só pela divulgação (positiva ou negativa) que aquele cliente pode fazer com relação à determinado serviço que the foi prestado (publicação em redes sociais, avaliação em sites relacionados), como também a um maior nível de conhecimento de seus direitos, fazendo com que os consumidores se tornem cada vez mais exigentes com relação à qualidade dos 
serviços prestados e também dos produtos adquiridos. SHIOZAWA (1993, p.47) menciona que: "O Código de Defesa do Consumidor garante que aquilo que antes o fornecedor encarava como uma concessão ou um favor torna-se um direito do consumidor".

Neste novo cenário, o consumidor assume uma posição mais forte com relação aos fornecedores e deixa de aceitar as imposições destes. O que antes ocorria com facilidade, por falta de conhecimento, se transformou em uma exigência do consumidor por um serviço melhor, com mais qualidade e visando sua satisfação. Caso isso não ocorra, o consumidor vai em busca de outro fornecedor.

\subsection{Marketing de Relacionamento}

De acordo com MARTINS (2006, p. 80) o marketing de relacionamento corresponde a:

"[...] uma filosofia de administração empresarial baseada na aceitação da orientação para o cliente e para o lucro, por parte de toda a empresa, e no reconhecimento de que se deseja buscar novas formas de comunicação para estabelecer um relacionamento profundo e duradouro para os clientes, prováveis clientes, fornecedores e todos os intermediários como forma de obter vantagem competitiva sustentável."

O marketing de relacionamento consiste em uma nova postura na interação da empresa prestadora de serviços com os seus clientes, uma vez que a empresa cada vez mais percebe que precisa dos consumidores para sobreviver e, com a satisfação de tais consumidores, sua possibilidade de crescimento é infinita. Segundo GONÇALVES; JAMIL; TAVARES (2002), o marketing de relacionamento surge como uma tentativa de lidar com os consumidores de uma forma diferente, identificando suas necessidades e oferecendo benefícios. De acordo com os autores GONÇALVES, JAMIL e TAVARES (2002), o marketing de relacionamento possui os seguintes objetivos: (i) a manutenção dos clientes satisfeitos, (ii) mensuração da satisfação; (iii) atuação na recuperação dos clientes, (iv) recebimento de feedback, (v) a oferta de serviços de qualidade e (vi) o desenvolvimento das relações públicas.

MCKENNA (1999) explica que o marketing de relacionamento é essencial para que uma empresa alcance a aceitação dos seus produtos e serviços, bem como a fidelidade do cliente. Nesta seara, a fidelização dos clientes a longo prazo é o objetivo final destas empresas, enquanto a atração de novos clientes é 
apenas uma etapa para o alcance deste objetivo. Em perspectiva, conclui-se que relacionamento de longo prazo tem relação direta com o grau de confiança que os clientes mantêm com a empresa. De acordo com os ensinamentos de PRIDE e FERREL (2001), a confiança está baseada na interação e no relacionamento sólido, para que isso ocorra é fundamental que as empresas respondam às necessidades dos clientes.

Assim sendo, entende-se que as empresas prestadoras de serviços devem buscar constantemente atingir as expectativas de seu cliente e, se possível superá-las, de forma a tornar aquele cliente um consumidor fiel. O atendimento de determinadas expectativas leva a satisfação e, consequentemente, gera mais confiança. GROCCO et al. (2006) explica que o marketing deve focar nos clientes atuais, bem como criar estratégias de manutenção e retenção desses clientes, buscando sempre conhecê-los estabelecendo relações mais próximas. Assim, o cliente passa a ser visto como um ativo de longo prazo, um investimento. Trata-se, portanto, do desenvolvimento de um marketing personalizado, que consiste em um diferencial competitivo para aquela empresa. No entanto, a empresa precisa entender que não é possível atender diferentemente todos os seus clientes, devendo direcionar a construção de relacionamento e os programas de fidelização para os clientes de maior valor e de maior potencial, sem que tal tratamento direcionado gere qualquer sentimento de discriminação entre seus consumidores. Neste sentido, as empresas devem investir na comunicação com os clientes utilizando as mais diversas tecnologias de informação disponíveis. Para KOTLER E ARMSTRONG (2003), o CRM (Customer Relationship Management) ou gerenciamento de relações com clientes é uma estratégia de negócios que visa entender, antecipar e administrar as necessidades dos clientes atuais e potenciais de uma organização. Desta forma, o desenvolvimento de um relacionamento sólido e duradouro com o cliente é essencial para que a empresa alcance o sucesso no negócio. 


\section{Metodos e procedimentos de coleta e de análise de dados do estudo}

Este capítulo tem por objetivo apresentar a metodologia empregada na realização desta pesquisa. Segundo GIL (2007, p. 17), pesquisa é definida como o "(...) procedimento racional e sistemático que tem como objetivo proporcionar respostas aos problemas que são propostos. A pesquisa desenvolve-se por um processo constituído de várias fases, desde a formulação do problema até a apresentação e discussão dos resultados".

\footnotetext{
"Diferentemente da pesquisa qualitativa, os resultados da pesquisa quantitativa podem ser quantificados. Como as amostras geralmente são grandes e consideradas representativas da população, os resultados são tomados como se constituíssem um retrato real de toda a população alvo da pesquisa. A pesquisa quantitativa se centra na objetividade. Influenciada pelo positivismo, considera que a realidade só pode ser compreendida com base na análise de dados brutos, recolhidos com 0 auxílio de instrumentos padronizados e neutros. A pesquisa quantitativa recorre à linguagem matemática para descrever as causas de um fenômeno, as relações entre variáveis, etc. A utilização conjunta da pesquisa qualitativa e quantitativa permite recolher mais informações do que se poderia conseguir isoladamente." (FONSECA 2002 p.20)
}

Para a análise do grau de satisfação dos clientes do restaurante Hollandaise, objeto deste estudo, foi realizada uma pesquisa quantitativa com questionário de perguntas fechadas, para coleta de dados, cujo procedimento será melhor explicado a seguir. A coleta de dados ocorreu no período de 01/04/2015 a 30/04/2015, durante os horários de almoço (12:00 horas às 15:00 horas) e jantar (19:00 horas às 22:00 horas) no Restaurante Hollandaise. Durante o referido período, 4.873 consumidores estiveram no estabelecimento, dentre os quais, 251 optaram por responder a pesquisa, totalizando $0,051 \%$ da amostra.

O questionário acima mencionado busca compreender a satisfação dos consumidores do restaurante Hollandaise nos quesitos de comida, bebida, atendimento, ambiente e relação custo-benefício. Além disso, foi solicitado o preenchimento dos seguintes itens: "Nome", "E-mail", "Gênero", "Data de Aniversário", "Idade", "Sugestões", "Data da Visita" e o principal "Grau de 
satisfação em relação a comida, bebida, atendimento, ambiente e relação custobenefício", de forma a entender melhor as necessidades do público que frequenta o local. Para a realização de tal pesquisa é importante se preocupar com a utilização de um questionário simples e de fácil entendimento, possibilitando um preenchimento rápido e eficaz. Cabe ressaltar que o questionário foi entregue aos clientes após o termino de suas refeições.

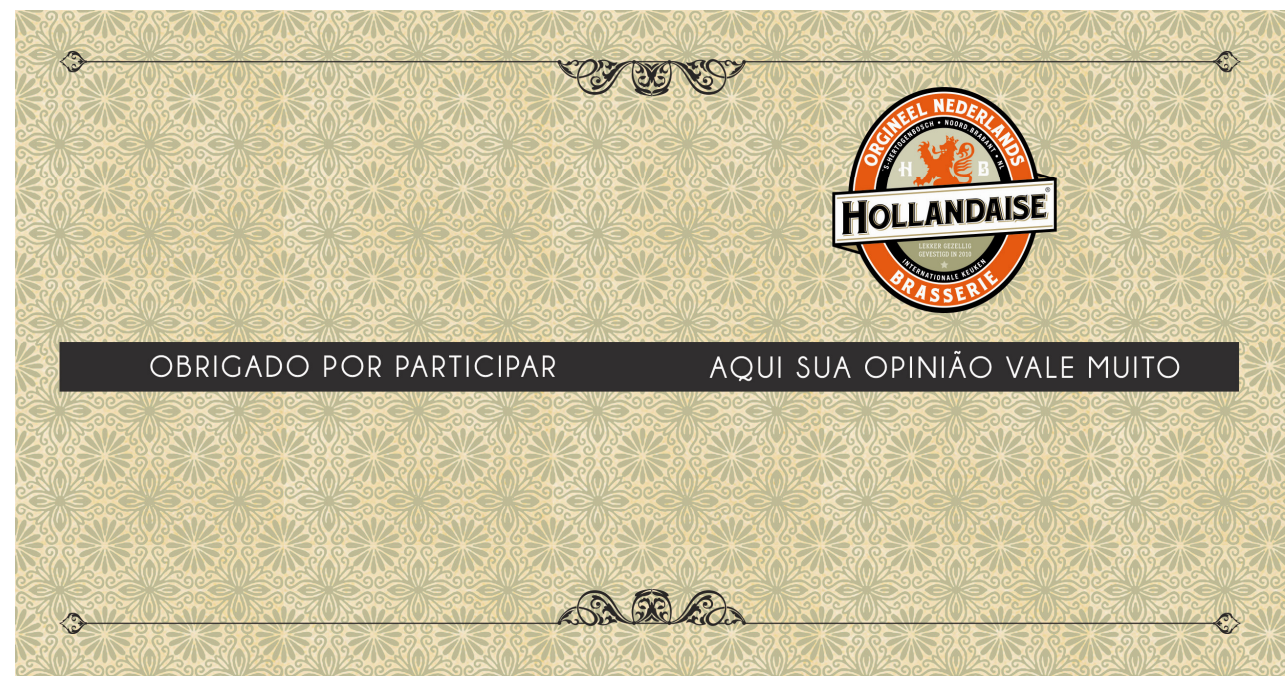

Figura 1: Pesquisa de Satisfação do Hollandaise - Frente

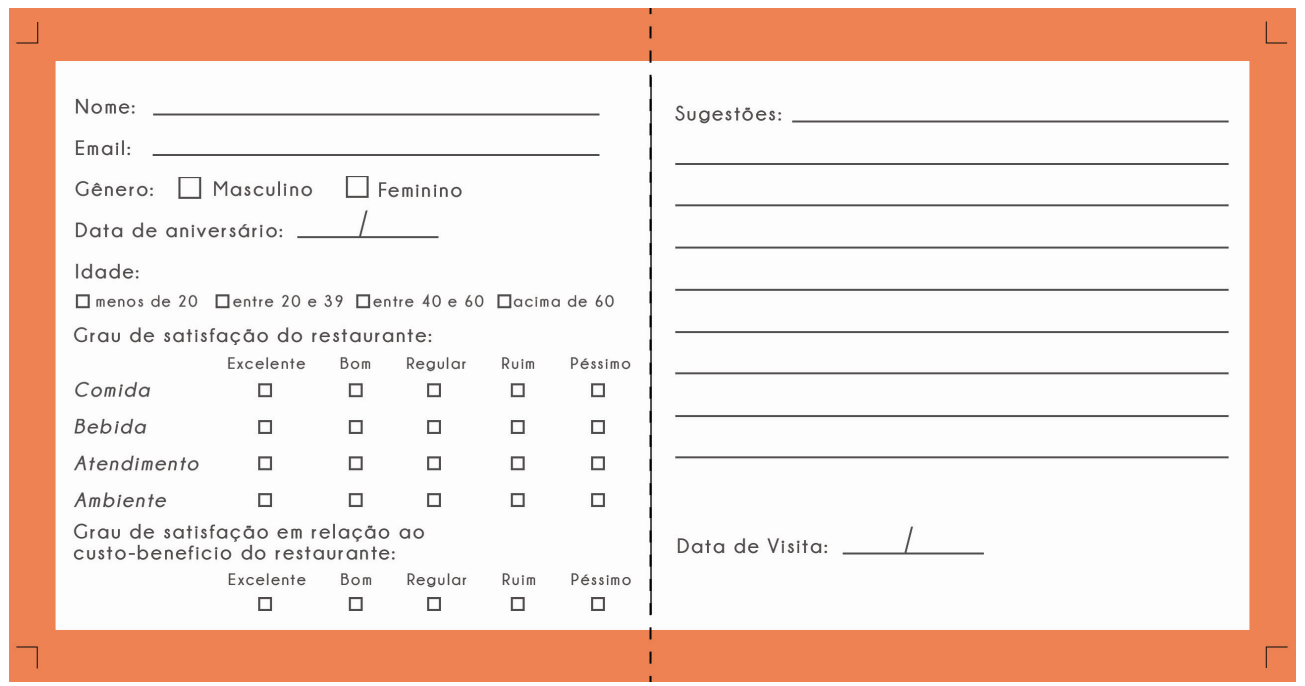

Figura 2: Pesquisa de satisfação Hollandaise - Verso 


\subsection{Fontes de informação selecionadas para coleta de dados no estudo}

As fontes de informação foram os consumidores do Restaurante Hollandaise, localizado no bairro da Barra da Tijuca, pertencente a cidade do Rio de Janeiro. Os procedimentos utilizados para a coleta de dados foi a elaboração de um questionário, que seguiu as seguintes etapas: (i) justificativa, (ii) definição dos objetivos, (iii) Redação das questões e afirmações, (iv) Revisão, (v) definição dos formatos, (iv) pré teste e (vii) revisão do questionário final. Segundo, MARCONI e LAKATOS (2003, p. 201) o questionário é definido como "Um instrumento de coleta de dados, constituído por uma série ordenada de perguntas, que devem ser respondidas por escrito e sem a presença do entrevistador". O questionário foi respondido pelos clientes após o término de suas refeições, juntamente com o pagamento de suas contas. Ao término da pesquisa, foram coletadas 251 respostas. Cada questionário foi inserido individualmente na ferramenta de pesquisa SURVIO. Por meio da referida ferramenta de pesquisa, foram obtidas análises estatísticas e gráficas dos resultados da pesquisa acima mencionada que serão abordadas no capítulo 4 .

\subsection{Limitações do Estudo}

A limitação desse estudo é que pode haver uma possibilidade de viés caso os respondentes não preencham a pesquisa de maneira correta (i) por falta de interesse no estudo apresentado, (ii) por resistência dos consumidores por considerarem ser uma perda de tempo, (iii) preenchimento incompleto do questionário. 


\section{Apresentação e análise dos resultados}

Nesse tópico iremos analisar os dados e resultados da pesquisa realizada, na qual os métodos foram apresentados no tópico 3.

Nota-se que 131 respondentes são do sexo feminino, 52,2\% da amostra coletada e 120 respondentes são do sexo masculino, 47,8\% da amostra coletada. Dessa forma, pode-se verificar que, apesar do número predominante de respondentes pertencer ao sexo feminino, existe um certo equilíbrio em relação aos questionários, conforme observa-se na tabela abaixo:

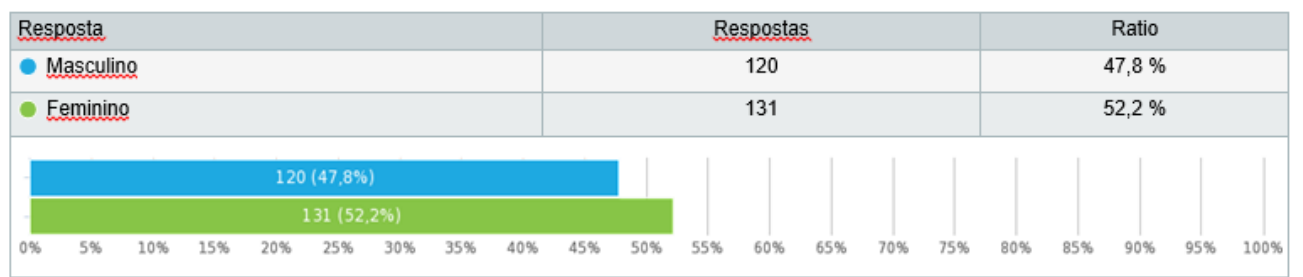

Tabela 1: Gênero dos consumidores

No que diz respeito à faixa etária, representando a maior parte dos respondentes 115 afirmam ter a faixa etária entre 40 e 60 anos, 45,8\% da amostra coletada. A faixa entre 20 e 39 é a segunda em número de respondentes com 102, 40,6\% da amostra coletada. Já 27 respondentes afirmam ser da faixa etária acima de 60 anos, 10,8\% da amostra coletada e 7 respondentes afirmam ter a faixa etária de menos de 20 anos, apenas 2,8\% da amostra coletada. Assim sendo, conclui-se que $86,4 \%$ dos respondentes pertencem a faixa etária de 20 a 60 anos e que a faixa etária predominante no restaurante pertence aos consumidores entre 40 a 60 anos, o que pode ser melhor observado na tabela a seguir. 


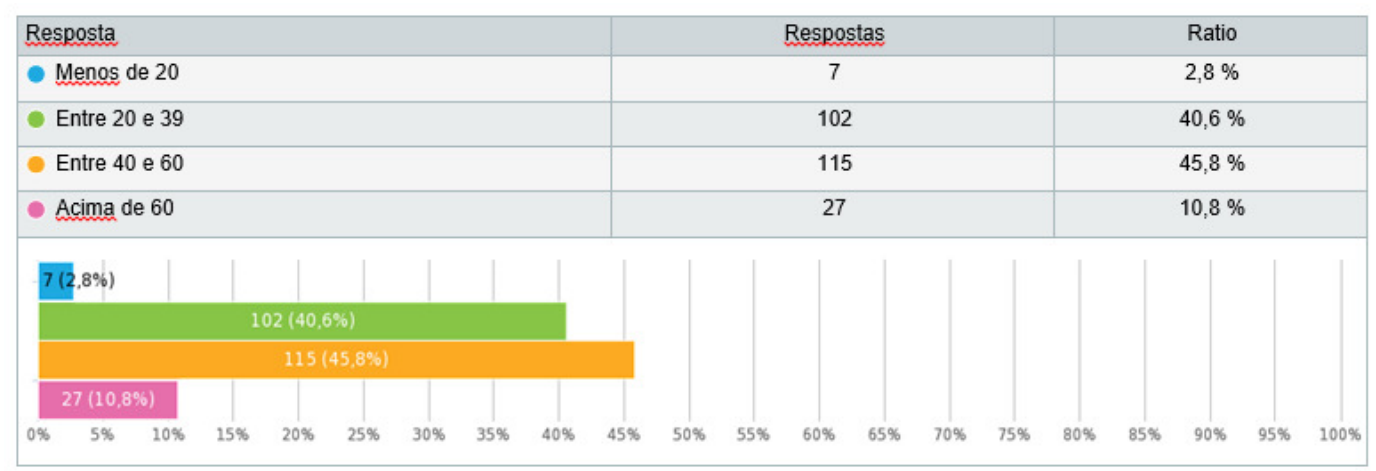

Tabela 2: Idade dos consumidores

Já com relação ao o grau de satisfação da comida, 191 respondentes a classificaram como "Excelente", 76,1\% da amostra, 57 respondentes classificaram o grau de satisfação da comida como "Bom", 22,7\% da amostra, apenas 1 respondente classificou o grau de satisfação da comida como "Regular", 0,4\% da amostra, nenhum dos respondentes classificou o grau de satisfação da comida como "Ruim" e apenas 2 respondentes classificaram o grau de satisfação da comida como "Péssimo", 0,8\% da amostra. Dessa forma, nota-se que $98,8 \%$ dos consumidores classificaram o grau de satisfação da comida como "Excelente/Bom" e apenas 1,2\% dos consumidores classificaram o grau de satisfação da comida como "Regular/Péssimo". Diante disso, conclui-se que somente 2 consumidores dentre os 251 respondentes classificaram como insatisfatório o grau de satisfação da comida oferecida pelo restaurante. Para melhor visualização, analisar o gráfico abaixo.

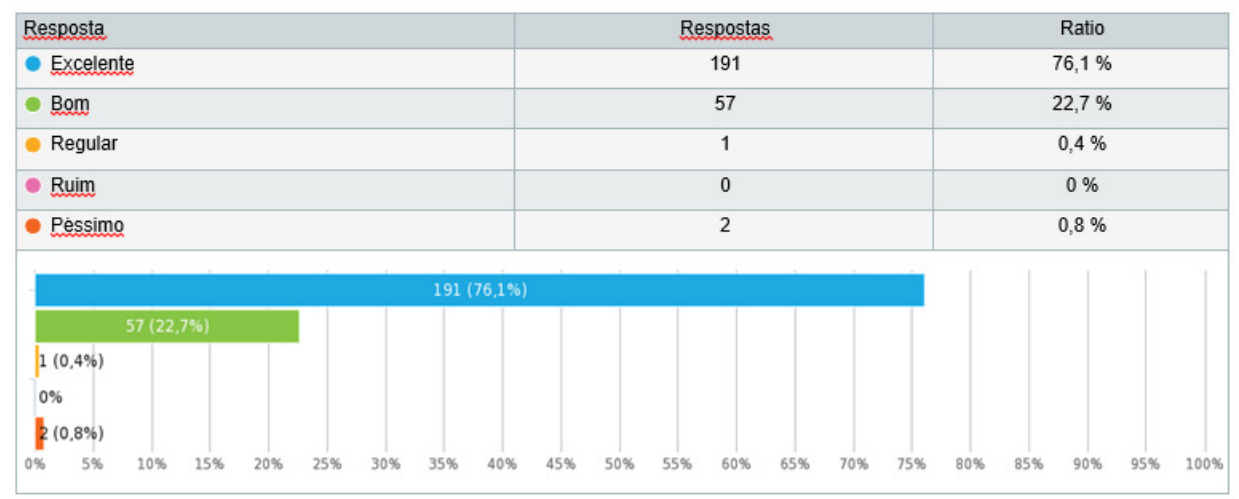

Tabela 3: Grau de satisfação da Comida 
No quesito bebidas, observa-se que 171 respondentes classificaram o grau de satisfação das bebidas como "Excelente", 68,1\% da amostra, 77 respondentes classificaram o grau de satisfação das bebidas como "Bom", $30,7 \%$ da amostra e apenas 3 consumidores dentro os 251 respondentes classificaram o grau de satisfação das bebidas como "Regular". Com tais valores, depreende-se que $98,8 \%$ dos respondentes classificaram o grau de satisfação das bebidas como "Excelente/Bom" e que nenhum consumidor ficou insatisfeito com a bebida ali oferecida. Mais uma vez, para melhor visualização, vale analisar as informações contidas na tabela a seguir.

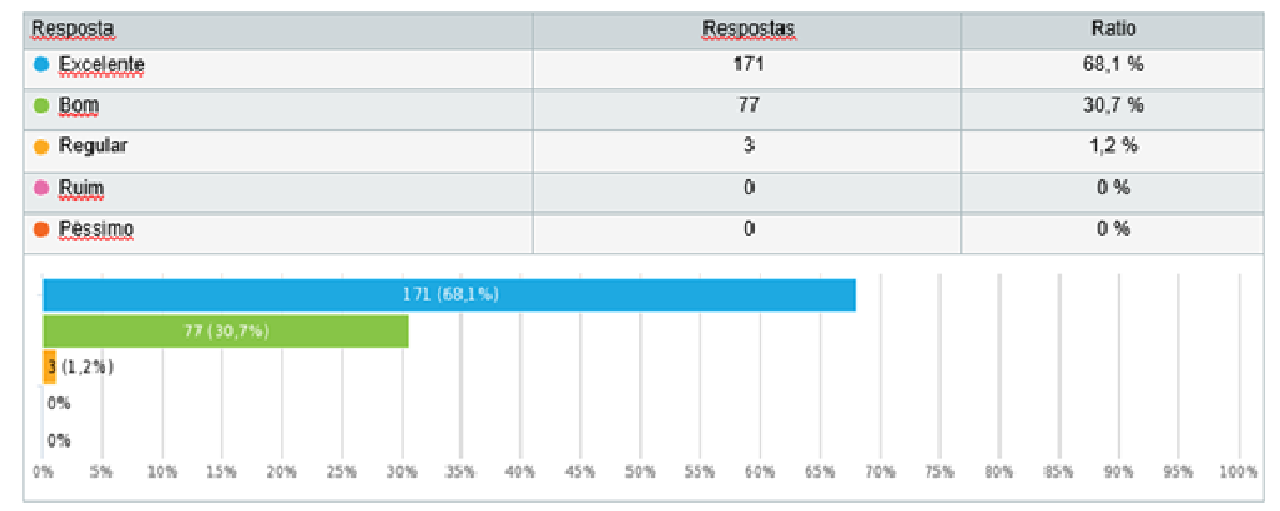

Acerca do atendimento oferecido no restaurante, verifica-se que 217

Tabela 4: Grau de satisfação da Bebida

respondentes classificaram o grau de satisfação com o atendimento como "Excelente", 86,5\% da amostra. Entre os respondentes, 32 destes classificaram o grau de satisfação em relação ao atendimento como "Bom", 12,7\% da amostra. Apenas 1 respondente classificou o grau de satisfação com o atendimento como "Regular", 0,4\% da amostra e 1 respondente classificou o grau de satisfação do atendimento como "Ruim", $0,4 \%$ da amostra. Mediante tais dados, nota-se que o grau de satisfação do atendimento foi classificado por 99,2\% dos respondentes como "Excelente/Bom" e apenas 1 consumidor manifestou insatisfação com o atendimento no local (ver tabela abaixo). 


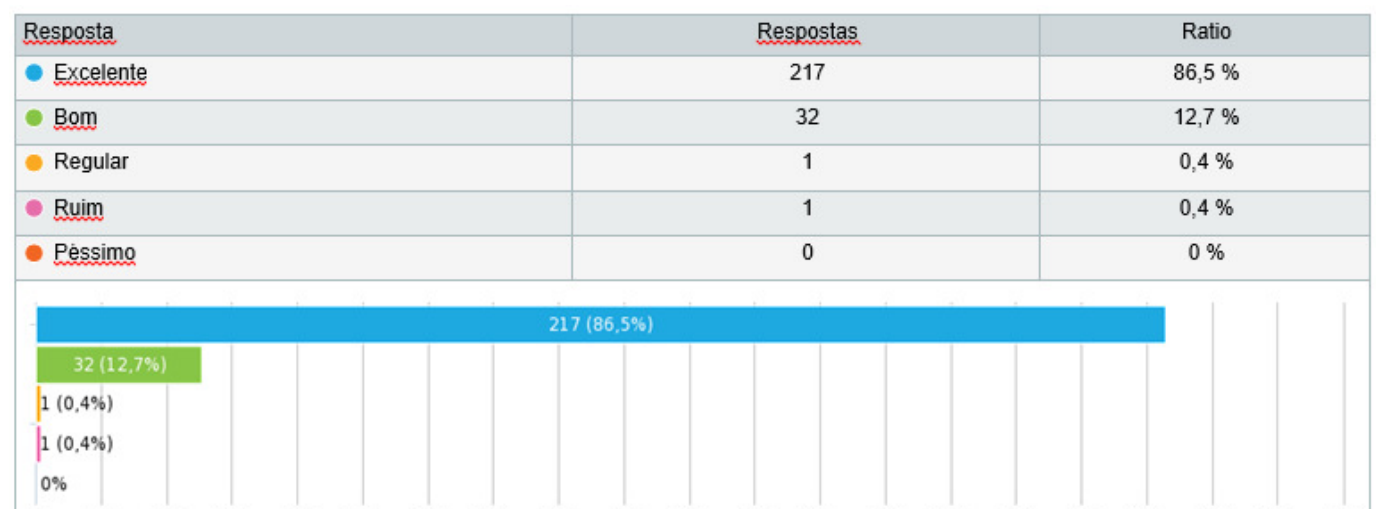

Tabela 5: Grau de satisfação do Atendimento

Em relação ao grau de satisfação com o ambiente, cita-se que 193 respondentes classificaram como "Excelente", 76,9\% da amostra, 54 respondentes classificaram o grau de satisfação do ambiente como "Bom", $21,5 \%$ da amostra e apenas 4 respondentes classificaram o grau de satisfação do ambiente como "Regular", 1,6\% da amostra. Assim sendo, nota-se que 98,4\% dos respondentes classificaram o grau de satisfação do ambiente como "Excelente/Bom" e que nenhum dos respondentes ficou insatisfeito com o grau de satisfação do ambiente oferecido, conforme demonstra-se na tabela a seguir.

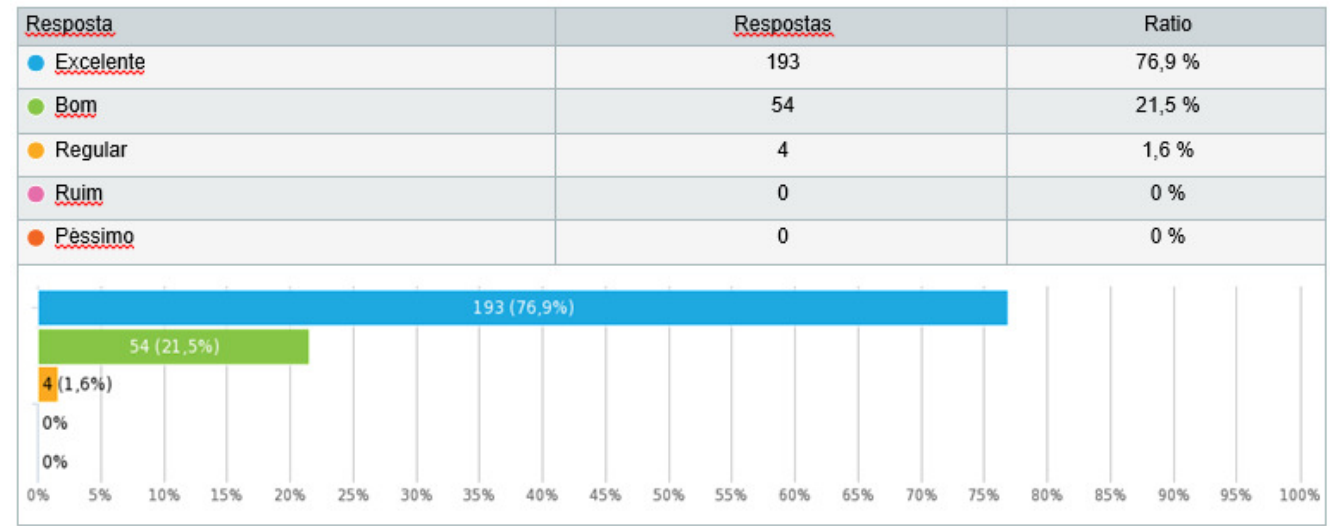


Em relação ao grau de satisfação dos consumidores com o custo-benefício 133 respondentes classificaram como "Excelente", 53\% da amostra, e 111 respondentes classificaram o grau de satisfação do custo-benefício como "Bom", $44,2 \%$ da amostra. Somente 6 respondentes classificaram o grau de satisfação do custo-benefício como "Regular", 2,4\% da amostra, um único respondente classificou o grau de satisfação do custo-benefício como "Péssimo", 0,4\% da amostra. Com isso, conclui-se que $97,2 \%$ dos respondentes classificaram o grau de satisfação do custo-benefício como "Excelente/Bom" e apenas 1 consumidor ficou insatisfeito com o grau de satisfação do custo-benefício ali oferecido, conforme tabela abaixo.

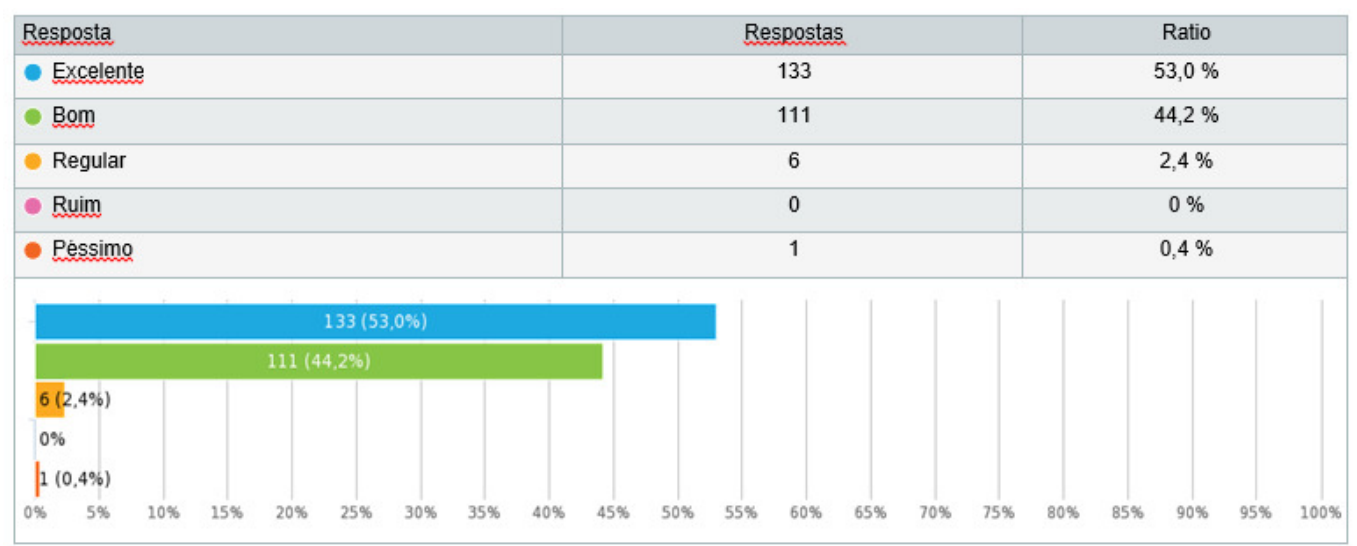

Tabela 7: Grau de satisfação do Custo-benefício

Além de tais informações, foi aberto um campo no questionário para que os clientes colocassem suas sugestões. Dentre elas, destacam-se as seguintes:

(i) Criação de um espaço infantil no restaurante

- "O espaço infantil é um diferencial na escolha de restaurantes para os pais com filhos pequenos"

- "Espaço para crianças";

(ii) Redução de taxa de serviço de $12 \%$ para $10 \%$

- "A taxa de serviço no Brasil costumeiramente é de $10 \%$. Por que o restaurante adota um percentual diferente? Sugiro que reduza para $10 \% "$ 
- "O serviço não deveria ser maior do que 10\%, 10\% é culturalmente no Brasil uma taxa de serviço aceitável, mais do que isso acho que queima a empresa";

(iii) Música ao vivo

- "Favor incluir no restaurante ambiente com música ao vivo"

(iv) Opções de pratos

- "Gostaria de ter mais opções de pratos: seria interessante ter algumas novidades no cardápio como sobremesas light/diet e sugestões do chef".

Ademais, vale destacar alguns elogios feitos pelos clientes, tais como:

(i) "Parabéns pelo atendimento, parabéns pela qualidade da comida, excelente ambiente e excelente custo-benefício, \$ucesso!"

(ii) "Parabéns, atendimento impecável, comida maravilhosa e ambiente perfeito"

(iii) "Parabéns pela excelente equipe e casa, desejo sucesso e prosperidade"

(iv) "Jantar inesquecível, espero que prosperem e que eu possa vir e partilhar os melhores momentos incontáveis vezes"

(v) "Sem dúvidas um dos melhores restaurantes do Rio de Janeiro".

Com a pesquisa acima detalhada, conclui-se que dentre os quesitos analisados, 72,12\% dos respondentes classificaram como "Excelente" o grau de satisfação do restaurante Hollandaise e $26,36 \%$ classificaram como "Bom" o grau de satisfação do restaurante Hollandaise. Desta forma, observa-se que $98,48 \%$ dos respondentes estão satisfeitos com os serviços oferecidos pelo restaurante. 


\section{Conclusões e recomendações para novos estudos}

O presente estudo demonstra que o grau de satisfação dos clientes do restaurante Hollandaise é extremamente alto, o que evidencia a constante preocupação de seus sócios com a fidelização do cliente final, buscando constantemente aprimorar o serviço ali oferecido e, consequentemente, ampliar seu retorno financeiro.

Assim sendo, com a realização da presente pesquisa pode-se notar que o grau de satisfação dos clientes só confirma o que a ferramenta "TripAdvisor" já havia demonstrado por meio do recebimento do certificado de excelência em 2015, com base nas avaliações dos consumidores.

Como forma de constante aprimoramento dos serviços ali oferecidos, é importante que a empresa invista em ações de marketing voltadas para a retenção dos clientes já conquistados, adquirindo, desta forma, um aliado na divulgação daquele estabelecimento. Tais ações devem ser cada vez mais personalizadas no sentido de fazer com que o cliente receba um tratamento diferenciado e sempre voltado a atender e satisfazer suas necessidades e expectativas.

Nota-se, ainda, que o consumidor se transformou uma forma de investimento a longo prazo para os prestadores de serviços e que, portanto, devem ser o foco de sua atuação, de forma a garantir que sua empresa esteja sempre em pleno crescimento. Para tanto, as empresas devem buscar investir em treinamento constante de seu pessoal, padronização do processo de prestação de serviço e acompanhamento da satisfação do consumidor por meio de pesquisas constantes.

Em relação aos consumidores que classificaram o serviço do Hollandaise como insatisfatório, teria que ser feita uma entrevista com eles para saber os motivos aparentes pois a pesquisa não se aprofundou a tal ponto. Vale ressaltar que para medir completamente o grau da qualidade dos serviços teria que avaliar todos os processos do restaurante. Seriam interessantes propor ações que resultariam em fidelização dos clientes como um desconto de $10 \%$ aos clientes que frequentarem o restaurante mais de 2 vezes por semana ou 
entregar vouchers aos clientes que dariam de cortesia um almoço/jantar. Dessa forma esses consumidores iriam promover o boca-a-boca do restaurante.

Principalmente no que diz respeito ao ramo de restaurantes, no qual o atendimento aos clientes é primordial, o estabelecimento deve sempre buscar um tratamento diferenciado, de forma a conquistar seus clientes e torna-los fiéis, procurando satisfazer suas necessidades, desejos e observar o comportamento dos consumidores. Leva-se em consideração que, os clientes estão cada vez mais exigentes e isso leva as empresas a enfrentarem maiores dificuldades para desenvolver seus negócios segundo ZENONE (2003). E para se tornar um sucesso é necessário que os serviços oferecidos ultrapassem as expectativas dos clientes segundo LOVELOCK (2001).

Por fim, destaca-se que o presente estudo poderá ser utilizado para futuros trabalhos acadêmicos com interesse no assunto, para empreendedores do ramo e para os proprietários do restaurante Hollandaise. 


\section{Referências Bibliográficas}

HOFFMAN, K. Douglas, Principios de Marketing de Serviços 3 ed. São Paulo: Cengage Learning, 2013.

COBRA, Marcos. Administração de marketing no Brasil. 3. ed. Rio de Janeiro: Elsevier, 2009.

GONÇALVES, Carlos Alberto; JAMIL, George Leal; TAVARES, Wolmer Ricardo. Marketing de relacionamento: Database Marketing. Rio de Janeiro: Axcel Books, 2002

KOTLER, Philip. Administração de marketing: análise, planejamento e controle. 5. ed. São Paulo: Atlas S. A, 1998.

, Philip. Marketing essencial: conceitos, estratégias e casos. 2. ed.

São Paulo: Pearson education S. A., 2005. Paulo: Pearson education, 2003.

LAS CASAS, Alexandre Luzzi (Coord.) et al. Novos rumos do Marketing. São Paulo: Atlas, 2001. MARTINS, Leandro. Marketing. São Paulo: Universo dos livros, 2006.

MARQUES, Wagner Luiz. Ciências empresariais. Livro on line, 2011 Disponível em: Acesso em: 15 de maio de 2012

RAPP, Stan; COLINS, Tom. Maximarketing: os vencedores. São Paulo: Makron Books, 1994.

ROCHA, Ângela da; CHRISTENSEN, Carl. Marketing: Teoria e prática no Brasil. 2. ed. São Paulo: Atlas, 1999. 
ROCHA, Lygia Carvalho. Orientação para clientes. Rio de Janeiro: Senac Nacional, 2004

SCHMITT, Bernd H. Gestão da experiência do cliente: uma revolução no relacionamento com os consumidores. Porto Alegre: Bookman, 2004

SLONGO, Luiz Antônio; LIBERALI, Guilherme. Marketing de relacionamento: Estudos, cases e proposições de pesquisa. São Paulo: Atlas, 2004.

VAVRA, Terry G. Marketing de relacionamento: aftermarketing. São Paulo, Atlas, 1993.

MARICATO, P. Como Montar e Administrar Bares e Restaurantes. São Paulo: Editora Senac, 2001.

MARICATO, P. Marketing para Bares e Restaurantes. Rio de Janeiro: Editora Senac Nacional, 2005.

KOTLER, Philip.; ARMSTRONG, G. Princípios de marketing. 9.ed. São Paulo: Prentice Hall, 2003

CAMPOS, V. F. . TQC: Controle da Qualidade Total (No estilo japonês). 6. ed. Belo Horizonte: Fundação Christiano Ottoni, Escola de Engenharia da UFMG, Belo Horizonte, 1992.

KOTLER, Philip. Administração de marketing. $5^{\circ}$ ed. São Paulo: Atlas, 1998

MCKENNA, Regis. Marketing de relacionamento. Rio de Janeiro: Campus, 1999.

LOVELOCK, Christopher. Serviços: marketing e gestão. São Paulo: Saraiva, 2001.

GIANESI, Irineu G. N.; CORRÊA, Henrique Luiz. Administração estratégica de serviços: operações para a satisfação do cliente. São Paulo: Atlas, 1996. 
KOTLER, Philip.; ARMSTRONG, G. Princípios de marketing. 9.ed. São Paulo: Prentice Hall, 2003

NICKLES, W. G.; WOOD, Marian Burk. Marketing: relacionamentos, qualidade e valor. Rio de Janeiro: LTC, 1999

LEVY, Michael; WEITZ, Barton A. Administração de varejo. São Paulo: Atlas, 2000.

SHIOZAWA, Ruy Sérgio Cacese. Qualidade no atendimento e tecnologia de informação. SãoPaulo : Atlas, 1993.

MARTINS, Leandro. Marketing. São Paulo: Universo dos livros, 2006.

GONÇALVES, Carlos Alberto; JAMIL, George Leal; TAVARES, Wolmer Ricardo. Marketing de relacionamento: Database Marketing. Rio de Janeiro: Axcel Books, 2002

79-93, jan./dez., 200987 Revista de Administração da Fatea, v. 2, n. 2, p. 999-999, jan./dez., 2009

MCKENNA, Regis. Marketing de relacionamento. Rio de Janeiro: Campus, 1999.

PRIDE, W. M.; FERREL, O. C. Marketing: conceitos e estratégias. Rio de Janeiro: LTC, 2001.

GROCCO, Luciano et al. Marketing: perspectivas e tendências. São Paulo: Saraiva, 2006.

KOTLER, Philip.; ARMSTRONG, G. Princípios de marketing. 9.ed. São Paulo: Prentice Hall, 2003.

GIL, A. C. Métodos e técnicas de pesquisa social. 5. ed. São Paulo: Atlas, 1999. Como elaborar projetos de pesquisa. 4. ed. São Paulo: Atlas, 
FONSECA, J. J. S. Metodologia da pesquisa científica. Fortaleza: UEC, 2002. Apostila.

MARCONI, M. de A.; LAKATOS, E. M. Fundamentos de metodologia científica. 5. ed. São Paulo: Atlas, 2003, p. 201

GROCCO, Luciano et al. Marketing: perspectivas e tendências. São Paulo: Saraiva, 2006.

CAMPOS, V. F. . TQC: Controle da Qualidade Total (No estilo japonês). 6. ed. Belo Horizonte: Fundação Christiano Ottoni, Escola de Engenharia da UFMG, Belo Horizonte, 1992.

KOTLER, Philip.; ARMSTRONG, G. Princípios de marketing. 9.ed. São Paulo: Prentice Hall, 2003

Restaurante Hollandaise - TripAdvisor

Disponível em: http://www.tripadvisor.com/Restaurant_Review-g303506d4299578-Reviews-Hollandaise-

Rio_de_Janeiro_State_of_Rio_de_Janeiro.html\#REVIEWS [Acessado em 23/05/2015]

TripAdvisor

Disponível em: http://www.tripadvisor.com.br/PressCenter-c6-About_Us.html [Acessado em 23/05/2015)]

CODEÇO, Fabio - Veja Rio "Falência de Restaurantes"

Disponível em: http://vejario.abril.com.br/materia/cidade/falencia-restaurantes-rj/ [Publicado em: 09/05/2014]

[Acessado em 05/05/2015]

Fluxo Consultoria

Disponível em:http://fluxoconsultoria.com/gestao-criacao-negocios/5-dicas-parasucesso-do-restaurante/

[Publicado em: 2015]

[Acessado em 23/05/2015] 
Paladar

Disponível em :http://blogs.estadao.com.br/luiz-americo-camargo/em-sp-poucosrestaurantes-ficam-antigos/

[Publicado em: 2015]

[Acessado em 20/05/2015]

Governo Brasileiro

Disponível em: http://www.brasil.gov.br/turismo/2014/06/alimentacao-em-barese-restaurantes-cresce-no-brasil

[Publicado em: 30/07/2014]

[Acessado em 05/05/2015]

Governo Brasileiro

Disponível em: http://www.brasil.gov.br/

[Publicado em: 30/07/2014]

[Acessado em 05/05/2015] 